\title{
ASSESSMENT OF THE ANISOTROPY EFFECT WHEN OPTIMISING THE DEEP DRAWING PROCESS BY NUMERICAL SIMULATION
}

\author{
${ }^{1}$ Miroslav TOMÁŠ, ${ }^{1}$ Emil EVIN \\ ${ }^{1}$ Technical University of Košice, Košice, Slovak Republic, EU, miroslav.tomas@tuke.sk, emil.evin@tuke.sk
}

https://doi.org/10.37904/metal.2021.4122

\begin{abstract}
The paper deals with numerical simulation when optimizing the production of gutter corner for rainwater systems. The deep drawing process has been numerically simulated using Pam Stamp software by ESI Group. Blank geometry, material quality and process parameters have been optimized. The elasto-plastic material model by Hollomon combined with orthotropic Hill 48 yield law were used in numerical simulation to describe material behaviour. These were defined on the results from tensile test, normal anisotropy ratio test and strainhardening test. Simulations were done for two different quality of the hot deep galvanized steel sheet $\mathrm{DX} 54 \mathrm{D}+\mathrm{Z}$ and DX56D+Z. As a results, process window for the gutter corner produced by deep drawing process have been found. Stated optimal process parameters were verified by experiment when lamination tooling concept has been adapted for production of the punch.
\end{abstract}

Keywords: Deep drawing, anisotropy, numerical simulation, optimization, verification

\section{INTRODUCTON}

Nowadays, in the time of digitization, computer aided systems have become a part of product design and their production process design as well. It resulted in a reduction of both production time and costs. The production process of deep-drawn parts is designed by CAE systems, which are based on numerical simulation. The finite element method is mainly used in the simulation of forming processes of metals and their alloys. $[1,2]$

When we create a simulation model as an artificial object, we can investigate its behavior under specified conditions during the simulation process. In the finite element method, both the die and the workpiece are divided into elements. Boundary conditions and process parameters (force, friction, velocity, etc.) are applied to the elements of die, while constitutive equations describing material behaviour (hardening curve, yield law, etc.) are applied to the elements of workpiece. As a result, the major and minor stresses and strains are calculated for each element and these are visualized on the workpiece's mesh. The other results can be shown as the thickness or thinning/thickening distribution over the workpiece, strain distribution over elements compared to the forming limit curve, etc. [3,4]

Today, 3D CAD or CAD/CAM software allows us to design complex components produced by deep drawing. Thus, new technologies known as Rapid Tooling for rapid production of deep drawing dies are applied to verify process parameters proposed by numerical simulation. These processes are based on additive and subtractive technologies, such as laser cutting, laser welding and CNC milling. To reduce manufacturing time and costs, various technologies for cutting, assembling, and joining metal sheets using the LOM principle are used. The development and improvement of the process chains for manufacturing of large tools was done at the Fraunhofer Institute for Material and Beam Technology. [5,6]

The aim of the paper was to find out the process window for the deep drawing of the gutter corner by numerical simulation. Next, to verify experimentally the results by applying rapid tooling principle to build the drawing die. 


\section{METHODS OF EXPERIMENTS}

To define the process window - material thickness and quality, blank shape - the deep drawing process of the gutter corner for rainwater system (Figure 1) was designed and numerically simulated. The draw-piece was complicated in shape due to a low inside radius and non-uniform material plastic flow in the straight die parts (high plastic flow) and inside radius (low plastic flow) when produced by deep-drawing. Thus, the aforementioned causes excessive stretching due to tensile radial and tangent stresses at the inside radius, and cracks may occur when an oversize blank-holding force or an excessive blank are applied.

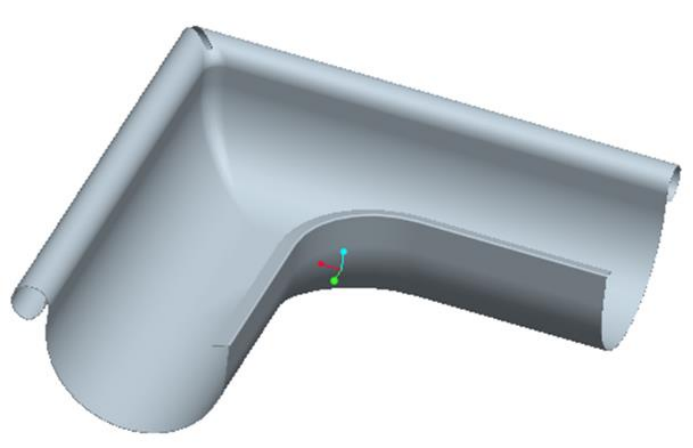

Figure 1 The draw-piece - gutter corner

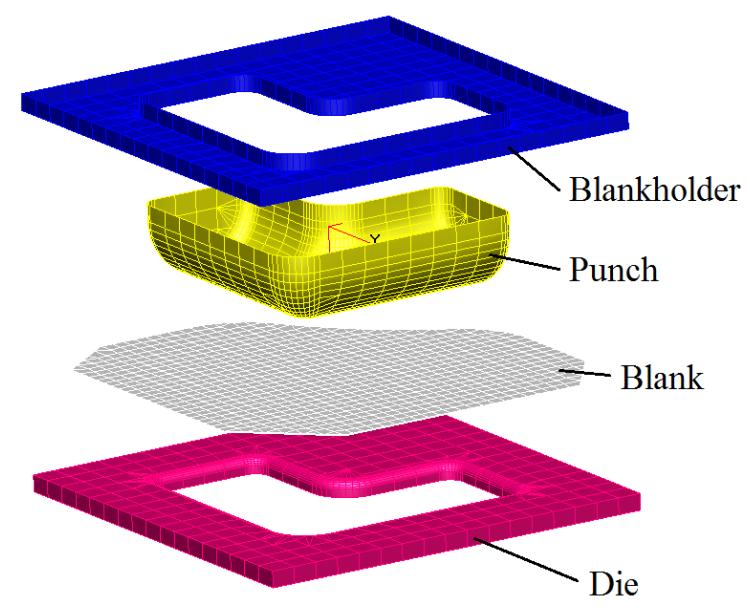

Figure 2 Simulation model of the deep-drawing process

The deep-drawing process numerical simulation of the gutter corner was performed on simulation model consisted of Die, Punch, Blankholder and Blank. The die setup after meshing the 3D CAD model in Pam Stamp $2 \mathrm{G}$ is shown in Figure 2. The Pam Stamp preprocessor was set with the following input data: basic material data (density, Young's modulus, Poisson's constant), blank thickness, plastic strain ratios $r^{\circ}, r_{45^{\circ}}$ and $r_{90^{\circ}}$, yield law defined by Orthotropic Hill 48 model and strain-hardening curve defined by Hollomon's law as follows:

$$
\sigma=K \cdot \varphi^{n}
$$

where: $\sigma$ - true stress $(\mathrm{MPa})$

$$
\begin{aligned}
& \mathrm{K} \text { - strength constant (MPa) } \\
& \mathrm{n} \text { - strainhardening exponent (-) }
\end{aligned}
$$

Hot deep galvanized steel sheet was considered for part production. Two quality of this steel were used in the simulations, which differed by formability parameters (Table 1) and thickness of 0.6 and $0.7 \mathrm{~mm}$.

Table 1 Mechanical properties of hot deep galvanized steels

\begin{tabular}{|c|c|c|c|c|c|c|c|}
\hline Quality & $\begin{array}{c}\mathbf{R}_{\text {p0.2 }} \\
(\mathbf{M P a})\end{array}$ & $\begin{array}{c}\mathbf{R m} \\
(\mathbf{M P a})\end{array}$ & $\begin{array}{c}\mathbf{r}_{0} \\
(-)\end{array}$ & $\begin{array}{c}\mathbf{r}_{45} \\
(-)\end{array}$ & $\begin{array}{c}\mathbf{r}_{90} \\
(-)\end{array}$ & $\begin{array}{c}\mathbf{K} \\
(\mathbf{M P a})\end{array}$ & $\begin{array}{c}\mathbf{N} \\
(-)\end{array}$ \\
\hline DX54D & $178 \pm 7$ & $298 \pm 6$ & 1.98 & 1.04 & 1.59 & $494 \pm 8$ & $0.207 \pm 0.008$ \\
\hline DX56D & $142 \pm 8$ & $297 \pm 5$ & 1.62 & 1.42 & 2.03 & $575 \pm 9$ & $0.274 \pm 0.006$ \\
\hline
\end{tabular}

Note: $\mathrm{R}_{\mathrm{p} 0.2,} \mathrm{Rm}, \mathrm{K}$ and $\mathrm{n}$ are averaged values from $0^{\circ}, 45^{\circ}$ and $90^{\circ}$

The blankholding force $220 \mathrm{kN}$ has been set, as calculated from the blankholding pressure $2 \mathrm{MPa}$ for drawing quality steel sheets. The friction between blank and blankholder, die and punch was set to 0.1 . The blank size and shape tested in numerical simulation are shown in Figure 3. 


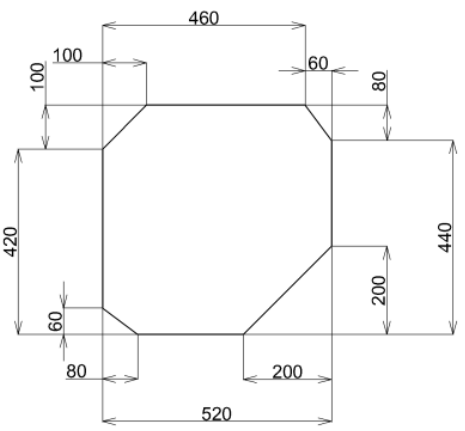

Blank shape A

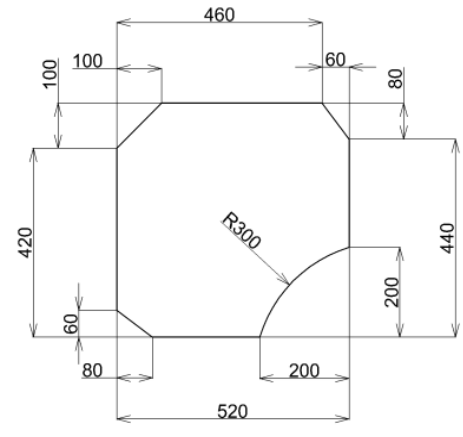

Blank shape B

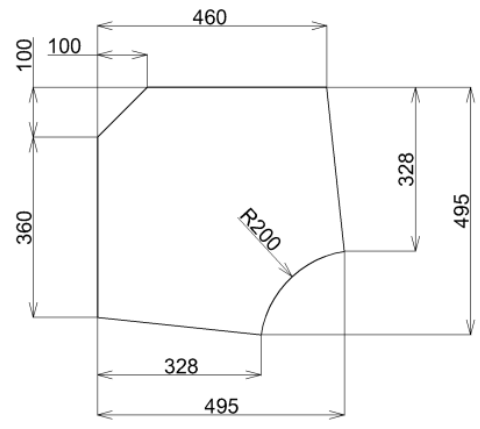

Blank shape C

Figure 3 Variants of the blank shape

The experimental drawing die shown in Figure 4 has been designed using the CAD/CAM system Creo to verify the optimal process parameters. The welded box structure of upper (drawing die) and lower (blankholder) die parts were created from thick steel sheets. Holes, i.e. functional surfaces in the drawing die and the blankholder, were cut by plasma and machined by milling.

The MELATO method was implemented to manufacture the punch [6]. The punch body was cut by plasma from a thick steel sheet of $20 \mathrm{~mm}$ thickness (punch base) and thin steel sheets of $5 \mathrm{~mm}$ and $1 \mathrm{~mm}$ (punch body). Laser was used to cut the lamellas, which were then stacked on the punch body and held together by pins. To create a smooth outer surface of the punch, a two-component polyester filler Galvaplast 77 was applied - Figure 5. After its hardening, the punch's outer surface was grinded to its final shape.

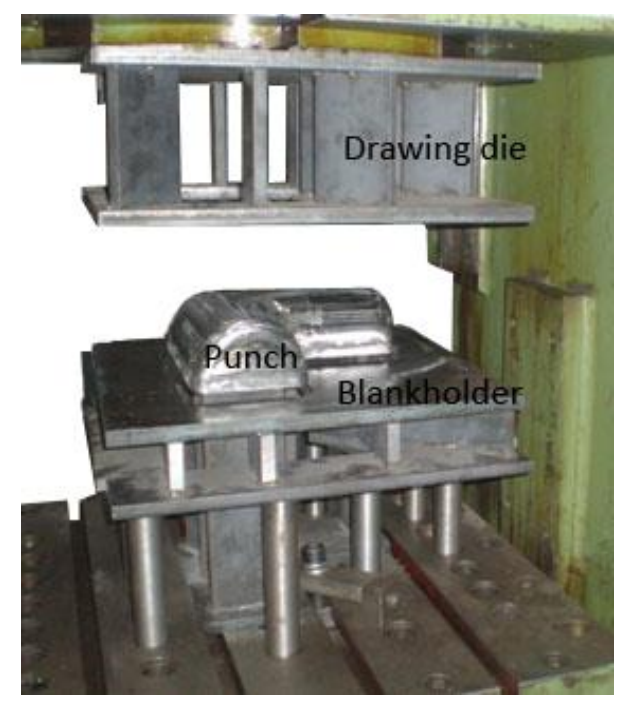

Figure 4 Experimental drawing die

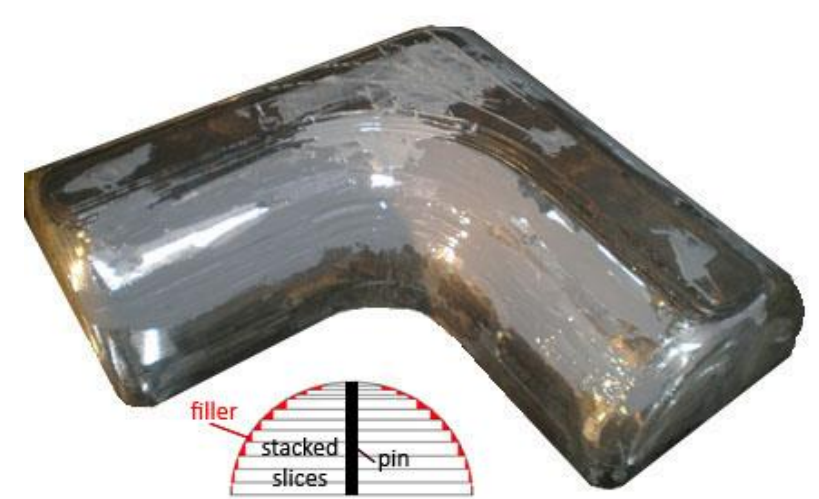

Figure 5 Punch made from lamellas

\section{RESULTS AND DISCUSSION}

The initial numerical simulations have been done for material DX54D+Z, thickness $0.6 \mathrm{~mm}$, blank shape $A$, friction $f=0.1$. The deep drawing process has been verified by the forming limit curve (FLC), calculated by the Keeler model in the Pam Stamp 2G software [7]. Calculated true strains have been compared to the FLC curve in "Zone by Quality" mode. The rupture risk has also been calculated based on the element's distance from the FLC curve (percentage; $100 \%$ - point on the FLC curve; > $100 \%$ rupture). It has been found the inside radius $\mathrm{R} 49$ is a critical area, due to cracks that have occurred here and the rupture risk has reached $136 \%$. 
Following numerical simulations have been focused to the blank shape optimization. The dimensions of the initial blank shape A have been calculated from the part dimensions and shape - outside curling and inside hem. The excessive material in the flange could make the plastic flow improper and blank fracture would occur. Based on the results of the numerical simulation, the second blank shape has been proposed and radius R300 applied to the blank shape A. It has been supposed to reduce radial stress and more homogeneous plastic flow. In the forming limit diagram only few elements exceeded FLC curve and the rupture risk dropped down to $112 \%$. The minimal blank thickness was $0.436 \mathrm{~mm}$, i.e. $31.9 \%$ thinning.

The result of the numerical simulation for the blank shape $C$ is shown in Figure 6 . Some elements have reached the marginal zone (between FLC and the dashed line) and two elements are lying on the FLC curve with a rupture risk of $100.6 \%$. The minimum blank thickness was $0.454 \mathrm{~mm}$, indicating a 27.8 percent thinning. This indicates that the deep drawing process has reached its limits. Some results of numerical simulations for material DX54D+Z, friction 0.1, and different blank shapes are shown in Table 2.

Table 2 Selected results of numerical simulations when optimizing the blank shape $\left(x\right.$-axis $=$ rolling dir. $\left.0^{\circ}\right)$

\begin{tabular}{|c|c|c|c|}
\hline Blank shape & $\begin{array}{c}\text { Minimum thickness } \\
(\mathbf{m m})\end{array}$ & $\begin{array}{c}\text { Thinning } \\
(\%)\end{array}$ & $\begin{array}{c}\text { Rupture risk } \\
(\%)\end{array}$ \\
\hline A & 0.411 & 37.7 & 136 \\
\hline B & 0.436 & 31.9 & 112 \\
\hline C & 0.454 & 27.8 & 101 \\
\hline
\end{tabular}
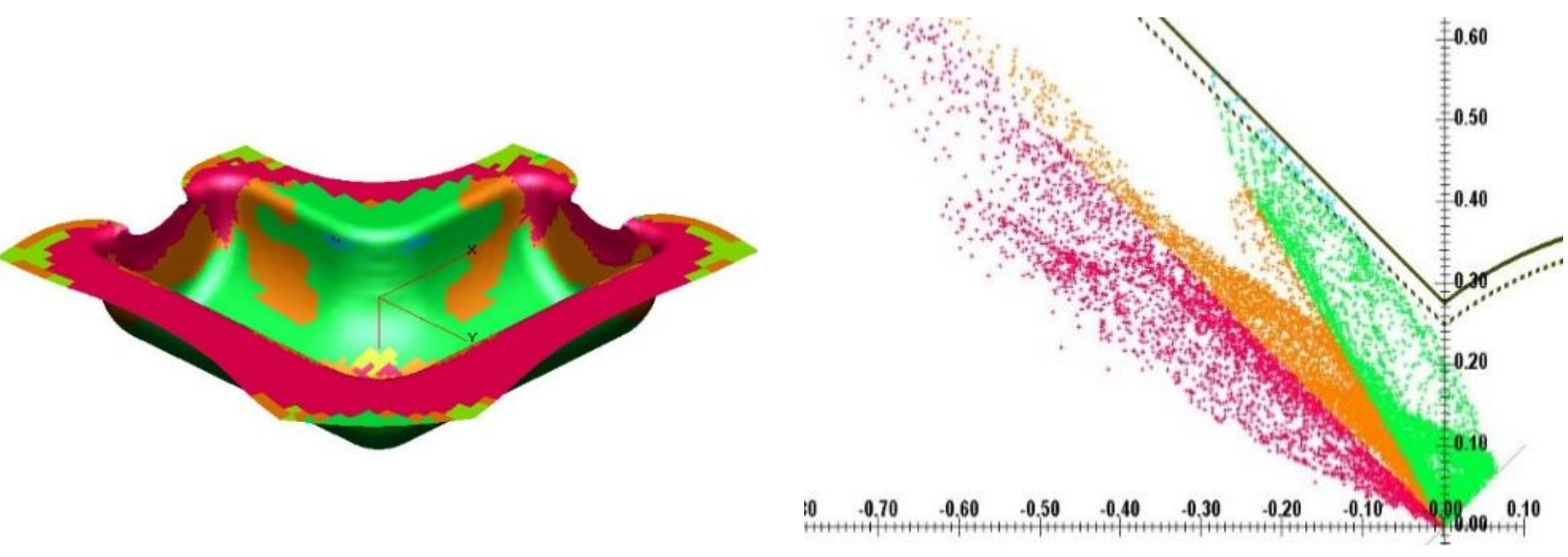

Figure 6 Forming Limit Diagram evaluation, $f=0.1$, blank $C, x=0^{\circ}$

Consequently, another improvement in the deep drawing process is required to reduce the rupture risk. There are more ways to make the deep drawing process more safe, i.e. without fracture: increasing material thickness, improving material drawability or utilizing the positive effect of material anisotropy.

Normal anisotropy is one of the important material characteristics necessary to consider when the deep drawing process is designed. The plastic strain ratio, as a drawability criterion, expresses the sheet metal's resistance to thinning during the deep drawing process. The higher value of the plastic strain ratio gives a higher resistance to thinning. Otherwise, when consider the planar anisotropy of the normal anisotropy ratio calculated as follows:

$\Delta r=\frac{1}{2} \cdot\left(r_{0}-2 \cdot r_{45}+r_{90}\right)$

where: $r_{0}, r_{45}$ and $r_{90}$ - plastic strain ratio measured in $0^{\circ}, 45^{\circ}$ and $90^{\circ}$ to rolling direction.

The lower values of $\Delta r$ are required. [8,9] 
Thus, directional values of the normal anisotropy ratio are important, mainly when box-shaped parts are deep drawn. The best results have been found when the highest values of normal anisotropy ratio (directions $0^{\circ}$ and $90^{\circ}$ ) go through the corners, where the highest degree of deformation occur [10]. Based on mentioned, the knowledge has been applied and the sheet metal rolling direction has been oriented $45^{\circ}$ to the $\mathrm{x}$ axis. This offers the normal anisotropy ratio highest value to the inside corner area where the highest strains have been identified. Consequently, the lower material thinning and lower rupture risk are expected as well.

The forming limit diagram for the blank shape $C$ when rolling direction $x=45^{\circ}$ is shown in Figure 7. The positive effect of the highest value the plastic strain ratio positioning to the critical area resulted in major and minor strains lowering. The minimal thickness in the critical area was 0.476 , i.e. $23.1 \%$ thinning with rupture risk $91.4 \%$. All elements have reached the safe zone of the forming limit diagram. The results of numerical simulations are summarised in Table 3.
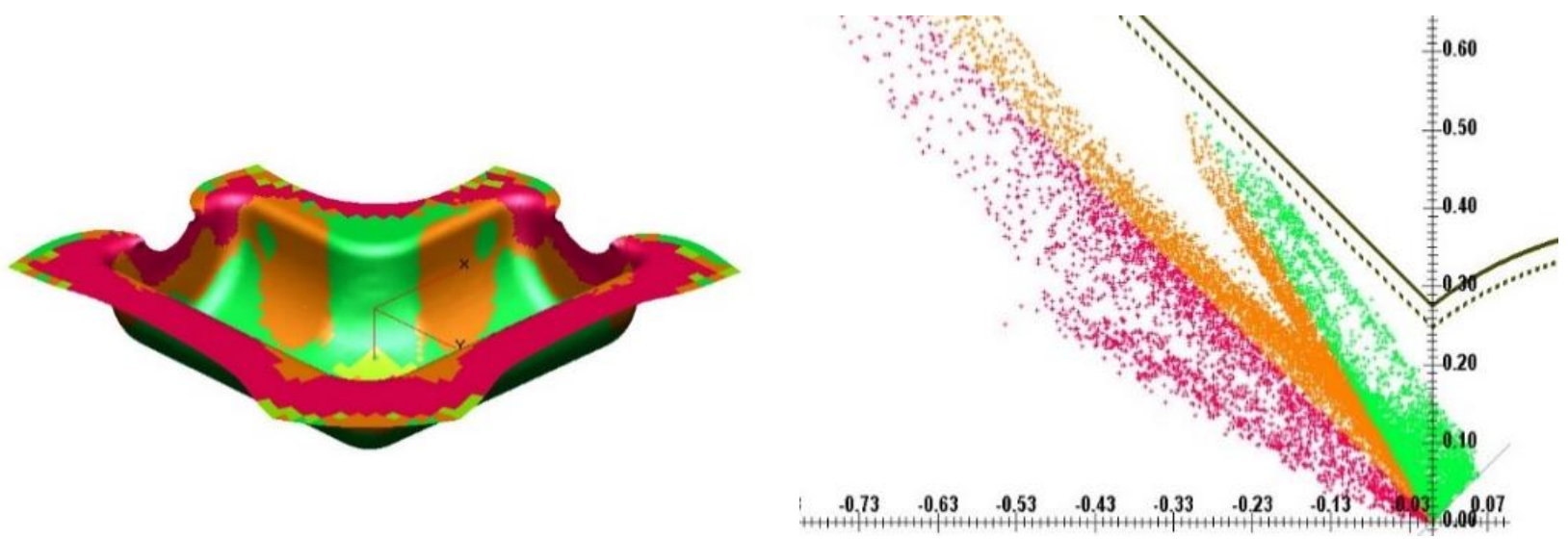

Figure 7 Forming Limit Diagram evaluation, $f=0.1$, blank $C, x=45^{\circ}$

Table 3 Selected results of numerical simulations when optimizing material quality and blank thickness

\begin{tabular}{|c|c|c|c|c|}
\hline $\begin{array}{c}\text { Material quality and } \\
\text { thickness }\end{array}$ & $\begin{array}{c}\text { Rolling direction } \\
\left.\mathbf{(}^{\circ}\right)\end{array}$ & $\begin{array}{c}\text { Minimum } \\
\text { thickness } \\
(\mathbf{m m})\end{array}$ & $\begin{array}{c}\text { Thinning } \\
(\%)\end{array}$ & $\begin{array}{c}\text { Rupture risk } \\
(\%)\end{array}$ \\
\hline $\mathrm{DX54D}+\mathrm{Z}, \mathrm{a}_{0}=0.7$ & $\mathrm{x}=0^{\circ}$ & 0.536 & 27.6 & 96.5 \\
\hline $\mathrm{DX56D}+\mathrm{Z}, \mathrm{a}_{0}=0.6$ & $\mathrm{x}=0^{\circ}$ & 0.461 & 22.8 & 97.9 \\
\hline $\mathrm{DX} 54 \mathrm{D}+\mathrm{Z}, \mathrm{a} 0=0.6$ & $\mathrm{x}=45^{\circ}$ & 0.476 & 23.1 & 91.4 \\
\hline
\end{tabular}

Note: blank $C, f=0.1$

The deep drawing process experimental verification has been done on the hydraulic press Fritz Muller BZE100, using an experimental drawing die of a welded box structure and the punch produced by the laminated tooling technology. The plastic foil used as a lubricant offers a friction coefficient $f<0.1$. [11,12]

The final drawn part of the gutter corner for blank shape $C$, material DX54D+Z, thickness $a_{0}=0.6 \mathrm{~mm}$ and anisotropy orientation $x=45^{\circ}$ is shown in Figure 8 and the result of numerical simulation is shown in Figure 9. Good agreement of the flange shape has been found when compare experimentally drawn part and numerically simulated.

The process window for material quality, thickness and blank shape is shown in Table 4. As it is shown, there more ways to reach the draw-piece, i.e. gutter corner without fracture. The most effective way appears to be material DX54D+Z, blank shape $C$, thickness $0.6 \mathrm{~mm}$, but the best value of plastic strain ratio must be oriented to the critical area, i.e. inside radius of the gutter corner $\left(x=45^{\circ}\right)$. 


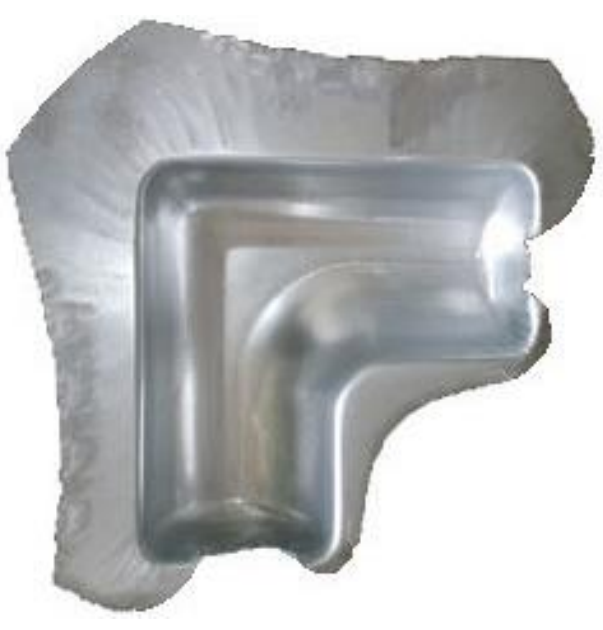

Figure 8 Experimentally drawn part

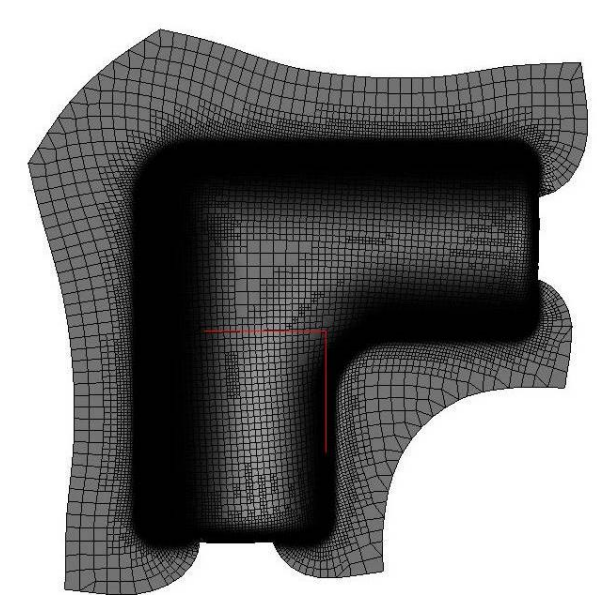

Figure 9 Numerically simulated drawn part

Table 4 The process window when optimizing the deep drawing process

\begin{tabular}{|c|c|c|c|c|c|c|}
\hline & \multicolumn{3}{|c|}{ DX54D+Z } & \multicolumn{3}{c|}{ DX56D+Z } \\
\hline Blank thickness/shape & $\mathrm{A}$ & $\mathrm{B}$ & $\mathrm{C}$ & $\mathrm{A}$ & $\mathrm{B}$ & $\mathrm{C}$ \\
\hline 0.6 & $\mathrm{X}$ & $\mathrm{X}$ & $\mathrm{X} / \checkmark$ & $\mathrm{X}$ & $\mathrm{X}$ & $\checkmark$ \\
\hline 0.7 & $\mathrm{X}$ & $\mathrm{X}$ & $\checkmark$ & $\mathrm{X}$ & $\checkmark$ & $\checkmark$ \\
\hline
\end{tabular}

Note: $\mathrm{f}=0.1 ;$ blankholder force $220 \mathrm{kN} ; \mathrm{x} / \vee-\mathrm{x}=0 \% \mathrm{x}=45^{\circ}$

\section{CONCLUSION}

The paper presents some results of numerical simulations realized when designing and optimizing the deep drawing process of the gutter corner. Numerical simulations allowed us to verify process parameters (friction, material thickness and quality) and determine the blank shape. When concluding the results of numerical simulations, the positive effect of the highest value of the plastic strain ratio when positioned in the critical area of the drawn part helped to make the deep drawing process safe. Consequently, the blank rupture risk decreased by $8 \%$. The results have been verified experimentally using a drawing die of a welded box structure with a punch made by a modified MELATO method. The presented method is suitable for large punch sizes in pre-production of new components. As a result, laminated tools can be made and modified in a timely and cost-effective manner.

\section{ACKNOWLEDGEMENTS}

The work has been accomplished under the grant projects VEGA 2-0080-19.

\section{REFERENCES}

[1] SCHREK, A., SVEC, P., BRUSILOVA, A. Formability of tailor-welded blanks from dual-phase and bake-hardened steels with a planar anisotropy influence. Strength of Materials. 2017, vol. 49, Issue 4, pp. 550-554.

[2] PERULLI, P., DASSISTI, M., CASALINO, G. Thermo-Mechanical Simulation of Hybrid Welding of DP/AISI 316 and TWIP/AISI 316 Dissimilar Weld. Materials. [online]. 2020, vol.13, 2088. Available from: https://doi.org/10.3390/ma13092088.

[3] VALEŠ, M., CHRÁŠŤANSKÝ, L., TATÍČEK, F., PAČÁK, T. Comparison of numerical simulation and deep drawing test of DP500 steel. In: 27th International Conference on Metallurgy and Materials (METAL 2018). Ostrava, Czech Republic: TANGER, 2018, pp. 501-506. 
[4] SUN, L., CAI, Z., HE, D., LI, L. Aluminum Alloy Sheet-Forming Limit Curve Prediction Based on Original Measured Stress-Strain Data and Its Application in Stretch-Forming Process. Metals. 2019, vol. 9, 1129.

[5] HIMMER, T., TECHEL, A., NOWOTNY, S., BEYER, E. Metal laminated tooling - a quick and flexible tooling concept. In: Laser Materials Processing Conference. San Francisco, California, USA, 2004. ISBN: 978-0-91203577-2.

[6] TECHEL, A. MELATO - Metal Laminated Tooling. Report nr.: BMBF 02 PP 1151/02 PP 1159, Stuttgart: Fraunhofer IRB Verlag. 2005, p. 81. ISBN: 978-3-8167-6928-6.

[7] Pam Stamp User's Guide, ESI Group, 2015.

[8] POLLÁK, L. Normal anisotropy as a deep-drawability criterion of steel sheets. Int. Sheet Metal Rev. 1999, vol. 1, no. 84.

[9] BETSOFEN, S.Y., SLAVOV, V.I., MATSNEV, V.N., KOSTYKOVA, O.S. Texture and anisotropy of a plastic flow in low-carbon deep-drawing steels. Russian Metallurgy. 2004, vol. 5, pp. 484-488.

[10] POLLÁK, L. Anisotropy of sheetmetals. Bratislava: Alfa,1st ed., 1978.

[11] HRIVŇÁK, A., EVIN, E. Formability of steel sheets. Košice: ELFA, 1st ed., 2004.

[12] TRZEPIECINSKI, T., LEMU, H.G. Recent Developments and Trends in the Friction Testing for Conventional Sheet Metal Forming and Incremental Sheet Forming. Metals. 2020, vol. 10, no. 47. 